\title{
Nosocomial outbreak of cryptosporidiosis in AIDS patients
}

\author{
Pernille Ravn, Jens D Lundgren, Poul Kjaeldgaard, Winnie Holten-Anderson, Niels Høilyng, \\ Jens Ole Nielsen, Johannes Gaub
}

Departments of Infectious Diseases and Clinical Microbiology, Hvidovre Hospital, DK-2650 Hvidovre, Denmark Pernille Ravn, $M D$, registrar Jens D Lundgren, $\mathrm{MD}$, registrar

Poul Kjaeldgaard, $M D$, registrar

Winnie Holten-Andersen, MD, senior registrar

Jens Ole Nielsen, PHD, senior consultant in infectious diseases

Johannes Gaub, PHD, consultant in infectious diseases

Department of Toxoplasmosis, Statens Seruminstitut, DK-2300 Copenhagen S, Denmark Niels Høilyng, MD, registrar

Correspondence to: Dr J Gaub, Department of Infectious Diseases 144,

Hvidovre Hospital,

DK-2650 Hvidovre,

Denmark.

BMF 1991;302:277-80
Abstract

Objective-To describe a nosocomial outbreak of cryptosporidiosis during four months after June 1989.

Setting-A department of infectious diseases in Copenhagen, seeing about half the patients with AIDS in Denmark.

Subjects -73 HIV antibody negative subjects and 60 antibody positive subjects admitted as inpatients during the transmission period of the outbreak (20 June-14 August), of whom 18 (17 with AIDS, one with AIDS related complex), developed cryptosporidiosis. Two further HIV negative subjects (one departmental secretary, one visiting relative) developed cryptosporidiosis.

Main outcome measures-Cryptosporidia in stool samples, clinical symptoms, CD4 cell count, HIV antigen concentration, chemotherapeutic treatment.

Results - The source of the outbreak was identified as ice from an ice machine in the ward, contaminated by an incontinent, psychotic patient with cryptosporidiosis picking out ice for cold drinks. The mean incubation time was at least 13 days - that is, twice that in HIV-negative patients. Of the 18 patients with AIDS who developed cryptosporidiosis, five recovered, two were symptomless carriers, three died of unrelated causes, and eight died after prolonged diarrhoea. Among the 57 exposed HIV antibody positive inpatients (excluding two patients and the index case with cryptosporidiosis diagnosed elsewhere), significantly more of those who developed symptomatic cryptosporidiosis received oral sulphonamides than those who $\operatorname{did} \operatorname{not}(91 \%, 10 / 11 v 48 \%, 21 / 44, \mathrm{p}<0.05)$.

Conclusions-The clinical and epidemiological findings indicate that infection was the consequence of very small inocula. Increased sensitivity to cryptosporidiosis may be an unrecognised side effect of oral sulphonamide treatment in patients with AIDS.

\section{Introduction}

Infection with cryptosporidium species is a cause of shortlived diarrhoea in immunocompetent subjects ${ }^{1-2}$ whereas in patients with AIDS it causes prolonged, often fatal, diarrhoea, for which no effective antiparasitic treatment exists. ${ }^{4}$ In Denmark cryptosporidiosis of more than one month's duration was seen in seven (3\%) of the first 231 Danish AIDS patients.

We report the epidemiological data and some clinical observations from a nosocomial outbreak of cryptosporidiosis in AIDS patients.

\section{Setting}

The department of infectious diseases provides health care services to about 100 patients with AIDS and about $500 \mathrm{HIV}$ antibody positive subjects without AIDS. The ward has 32 beds in one bedded and two bedded rooms, about half of which are occupied by patients with HIV related diseases. Cryptosporidiosis was diagnosed in one patient in the department in 1987 , in three in 1988 , and in one during the first five months of 1989.

\section{Outbreak}

On 19 June 1989 a 29 year old, psychotic homosexual man was admitted from a closed psychiatric ward. He was HIV antibody positive, and AIDS was diagnosed on the basis of progressive multifocal leucoencephalopathy. He had watery diarrhoea and faecal incontinence, and cryptosporidia were found in a stool sample taken on 20 June. He was grossly negligent about basic hygiene, including washing his hands, and was confined to his room, but as no physical restraint could be used he was repeatedly observed in the ward; on at least two occasions he was seen picking ice for soft drinks with his hands from an ice machine situated in a storeroom in the ward.

During the subsequent 10 weeks 17 cases of cryptosporidiosis were diagnosed, with a peak incidence about seven weeks after the arrival of the index case. Cryptosporidiosis was diagnosed in another two patients 14 and 17 weeks after the arrival of the index case. The cases had one common exposure. During the hot summer of 1989 ice cooled soft drinks, with ice from the ice machine in the ward, were served to patients, staff, and visiting relatives both in the ward and in the outpatient department.

\section{Measures taken}

The ice machine was closed down on 14 August and cleaned, and the ice was subsequently used only for cooling blood samples. Isolation procedures for patients with cryptosporidiosis (wearing gloves and gowns for close contact) were not changed, and no other supplies of food and beverage were changed. Regional and national health authorities were notified of the outbreak. The new cases seen thereafter could all be traced to exposure during admission or visits to the outpatient department from 20 June to 14 August (the transmission period).

The HIV antibody positive patients who had been admitted as inpatients during the transmission period were asked to deliver a faecal sample for examination for cryptosporidium oocysts, irrespective of their symptoms. Of 60 such inpatients, 38 (63\%) delivered a sample. Outpatients, HIV antibody negative inpatients, and staff members with symptoms of cryptosporidiosis were also offered a stool examination.

All stool samples were examined for cryptosporidia with a modified Ziehl-Neelsen staining technique of faecal smears. ${ }^{6}$ 


\section{Patients}

During the transmission period 73 HIV antibody negative and 60 antibody positive subjects were admitted as inpatients. Among the $60 \mathrm{HIV}$ antibody positive inpatients, 14 developed symptomatic cryptosporidiosis and two asymptomatic cyst excretion; six patients with symptoms and 16 without had negative results on stool examination, and $22 \mathrm{HIV}$ antibody positive patients did not deliver a faecal sample for examination. Four cases of cryptosporidiosis were diagnosed in HIV antibody positive patients, whose only contact with the department in the transmission period was visits to the outpatient department (figure).

The 20 cases of cryptosporidiosis were identified. They included HIV antibody negative subjects with diarrhoea: a secretary employed in the department and a visiting relative. The $18 \mathrm{HIV}$ antibody positive patients with cryptosporidiosis comprised 17 patients with AIDS and one with AIDS related complex. One of the patients with AIDS had recovered from an

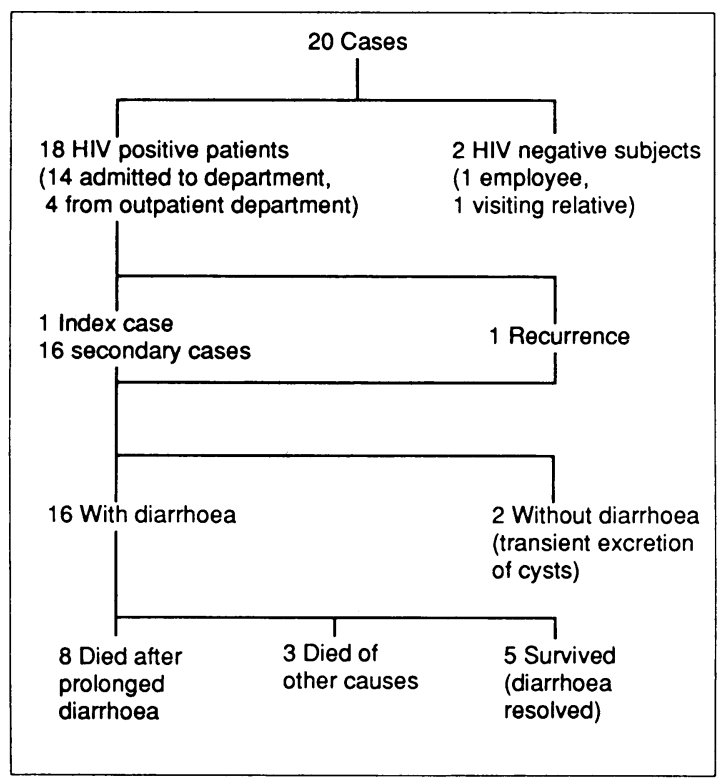

Summary of cases involved in the outbreak of cryptosporidiosis, fune 1989 to October 1989

TABLE I-Risk factors for acquiring cryptosporidium diarrhoea in exposed HIV antibody positive patients

\begin{tabular}{|c|c|c|c|}
\hline & $\begin{array}{l}\text { Inpatients } \\
\text { with } \\
\text { diarrhoea } \\
(\mathbf{n}=11)\end{array}$ & $\begin{array}{l}\text { Inpatients } \\
\text { without } \\
\text { diarrhoea }^{\star} \\
(n=44)\end{array}$ & p Value ${ }^{\star} \dagger$ \\
\hline Mean (SD) age (years) & $40(8 \cdot 8)$ & $38(10 \cdot 4)$ & NS \\
\hline No (\%) with AIDS & $11(100)$ & $32(73)$ & $\leqslant 0 \cdot 1$ \\
\hline Mean $(\mathrm{SD}) \mathrm{CD} 4$ cells $\left(\times 10^{\mathrm{s}} / \mathrm{l}\right)$ & $43(40 \cdot 8)$ & $168(227)$ & 0.08 \\
\hline No (\%) positive for HIV antigen $\ddagger$ & $8(73)$ & $24(57) \S$ & NS \\
\hline Mean (SD) exposure (days) & $17(12)$ & $15(9)$ & NS \\
\hline No $(\%)$ taking oral zidovudine & $7(64)$ & $24(55)$ & NS \\
\hline No (\%) taking oral sulphonamides $\|$ & $10(91)$ & $21(48)$ & $<0.05$ \\
\hline No $(\%)$ taking oral corticosteroids & $4(36)$ & $9(20)$ & NS \\
\hline
\end{tabular}

TABLE II -Selected characteristics of 18 HIV antibody positive patients with cryptosporidiosis. Values are medians (ranges)

\begin{tabular}{lcccc}
\hline & $\begin{array}{c}\text { With no diarrhoea } \\
(\mathbf{n}=2)\end{array}$ & $\begin{array}{c}\text { Recovering from } \\
\text { diarrhoea } \\
(\mathbf{n}=5)\end{array}$ & $\begin{array}{c}\text { Dying from other } \\
\text { causes } \\
(\mathbf{n}=3)\end{array}$ & $\begin{array}{c}\text { Dying mainly } \\
\text { from diarrhoea } \\
(\mathbf{n}=8)\end{array}$ \\
\hline CD4 cells $\left(\times 10^{\circ} / 1\right)$ & $248(48-448)$ & $91(7-304)$ & $5(5-96)$ & $40(0-112)$ \\
HIV antigen $(\mathrm{U} / \mathrm{l})$ & $331(325-336)$ & $\begin{array}{c}622(77->1000) \\
9(2-90)\end{array}$ & $\begin{array}{l}\text { Negative } \\
6(6-20)\end{array}$ & $\begin{array}{c}382(75-1000) \\
\text { Duration of diarrhoea (days) }\end{array}$ \\
\hline
\end{tabular}

episode of cryptosporidiosis six months before this epidemic.

Of the $60 \mathrm{HIV}$ positive patients, only 57 were exposed to cryptosporidium infection as two patients in addition to the index case had cryptosporidiosis diagnosed elsewhere before any contact with the department. The attack rate-that is, cases of symptomatic cryptosporidiosis per number of patients exposedamong HIV antibody positive inpatients was thus $19 \%$ (11/57); among HIV antibody negative inpatients $0 \%$ (0/73); and among HIV antibody positive outpatients almost $0.5 \%$ ( 4 cases in about 700 visits).

\section{Determinants of infection}

The records of all HIV antibody positive patients exposed to cryptosporidium transmission as inpatients were reviewed for risk factors for acquiring symptomatic cryptosporidiosis (table I). The symptomless carriers were excluded from the analysis as other carriers may have been missed among the 22 HIV antibody positive inpatients who did not deliver a stool sample. We found insignificant trends towards higher CD4 counts, less frequent HIV antigenaemia, and fewer AIDS cases among the 44 patients without symptomatic cryptosporidiosis. Ten patients (91\%) with cryptosporidiosis compared with only 21 patients (48\%) without cryptosporidium diarrhoea $(\mathrm{p}<0.05)$ received oral sulphamethoxazole-trimethoprim treatment or prophylaxis for Pneumocystis carinii pneumonia, or both, or sulphadiazine-pyrimethamine treatment for cerebral toxoplasmosis at some time during the transmission period.

\section{Clinical course}

Among the $16 \mathrm{HIV}$ antibody positive patients with diarrhoea the outcomes were as follows: in five $(31 \%$, $95 \%$ confidence interval $11 \%$ to $59 \%$ ) the diarrhoea resolved, three $(19 \%, 4 \%$ to $46 \%)$ had diarrhoea but died of other causes, and eight $(50 \%, 25 \%$ to $75 \%)$ died after prolonged diarrhoea. The remaining two HIV antibody positive patients with cryptosporidiosis, who did not have diarrhoea, were without cryptosporidium oocysts on faecal re-examination. In the two HIV antibody negative patients the diarrhoea resolved after two and 10 days respectively.

\section{Determinants of outcome of infection}

Table II shows selected clinical and paraclinical data on the $18 \mathrm{HIV}$ antibody positive patients in the outbreak. Of the five patients whose diarrhoea resolved, three recovered spontaneously after diarrhoea lasting two, three, and nine days respectively. Two patients with prolonged diarrhoea recovered after treatment with hyperimmune bovine colostrum or zidovudine for 46 and 90 days respectively.

The HIV antigen concentration and CD4 counts did not differ significantly between the five patients who recovered and the eight who died of cryptosporidiosis; most of the patients had a content of $<100$ million CD4 cells/l.

\section{Attempts at treatment}

The following treatments were tried, with negligible or no effect: sodium antimony glyconate (Pentostam) $5 \mathrm{mg} / \mathrm{kg}$ intravenously plus $5 \mathrm{mg} / \mathrm{kg}$ orally per day (three patients), roxithromycin (three), spiramycin (five), clindamycin plus quinine (one), and intravenous interleukin 2 (one). Hyperimmune bovine colostrum and placebo were given to eight patients as part of a placebo controlled, blinded, crossover clinical trial (N Højlyng, personal communication). Table III summarises the treatment with zidovudine, which had no consistent beneficial effect. 


\begin{tabular}{lcccc}
\hline & $\begin{array}{c}\text { With no diarrhoea } \\
(\mathbf{n}=2)\end{array}$ & $\begin{array}{c}\text { Recovering from } \\
\text { diarrhoea } \\
(\mathbf{n}=5)\end{array}$ & $\begin{array}{c}\text { Dying from } \\
\text { other causes } \\
(\mathbf{n}=3)\end{array}$ & $\begin{array}{c}\text { Dying mainly from } \\
\text { diarrhoea } \\
(\mathbf{n}=8)\end{array}$ \\
\hline $\begin{array}{l}\text { No treatment } \\
\text { Pre-existing and continuing } \\
\text { treatment }\end{array}$ & 2 & 2 & 3 & 1 \\
\begin{tabular}{l} 
Treatment started during diarrhoea \\
\hline
\end{tabular} & 2 & 1 & & 6 \\
\hline
\end{tabular}

\section{Incubation time}

In six patients (ignoring the two late cases of patients with minimum incubation times of 55 and 77 days) the mean interval between their last contact with the department and the onset of diarrhoea was 13 days (range 2-31 days), implying that if they were infected in the department the incubation time must have been on average at least 13 days; as it is a minimum estimate the incubation time was most likely longer.

\section{Discussion}

Among the 19 secondary cases of patients in this outbreak, 17 had diarrhoea or asymptomatic carriage of cryptosporidia diagnosed within two weeks after the interruption of the hypothetical route of transmission. Two cases of cryptosporidiosis occurred 8 and 11 weeks after closure and disinfection of the ice machine, and it is impossible to tell whether they resulted from nosocomial spread with a long incubation or latency period or represented non-epidemic cases. Another of the 17 cases could be either a nosocomial reinfection or a recurrence of cryptosporidiosis. Recognising these uncertainties, we report the details of all 19 cases of infection possibly acquired in the department, plus the index case.

Direct evidence incriminating the ice machine in the ward is lacking, as it was closed and disinfected before it was realised that cryptosporidia might have been detected after filtration of the water it contained. ${ }^{.8}$ Our contention that ice from the machine transmitted cryptosporidia around in this outbreak, however, is supported by strong circumstantial evidence. Firstly, the patient who was the index case was observed picking ice with his hands, which on other occasions were observed by other staff members to be soiled with faeces. Secondly, the outbreak included a visiting relative and an employee who shared soft drinks but not food with the patients. As the employee was a secretary infection through direct patient contact was ruled out; the visiting relative was the wife of a patient with fever of unknown origin, unrelated to HIV infection. Thirdly, the outbreak included four patients whose only contact with the department during the transmission period were visits to the outpatient department. Ice from the ice machine was used in soft drinks for those attending the outpatient department during the transmission period. Fourthly, transmission was stopped after strict confinement of the index case to his room and closure of the ice machine despite the continued presence in the ward, for several months, of patients infected with cryptosporidia during the outbreak. No other departmental routines were changed.

During the course of this outbreak several important clinical observations were made. The minimum mean incubation time of 13 days is about twice as long as the two to five days and $7 \cdot 2$ days previously reported. ${ }^{39}$ Our incubation times may represent a biased selection of the minimum incubation times observed. As the bias consists of exclusion of two patients with very long minimum incubation times a less biased estimate would yield an even longer incubation time.

In a study of cryptosporidiosis in Finns going to Leningrad $^{9}$ no case of asymptomatic carriage was detected, and the authors suggested that such cases are rare. We found two cases of asymptomatic carriage among 18 symptomless patients examined for cryptosporidia, and together with other studies in AIDS patients $\mathrm{s}^{10-12}$ this indicates that asymptomatic carriage of cryptosporidia is a frequent occurrence in exposed AIDS patients, just as it is in non-immune children in locations where cryptosporidiosis is hyperendemic. ${ }^{13}$ This might explain the longer incubation time in our AIDS patients with cryptosporidiosis, as diarrhoea could result from aggravation of the immune deficiency in a symptomless HIV antibody positive carrier, giving the appearance of a long incubation time. Alternatively, however, a long incubation time may result, at least in part, from infection with relatively small inocula, too small to establish infection in immunocompetent subjects. This is consistent with three of our clinical observations. Firstly, we saw no cases of symptomatic cryptosporidiosis among HIV antibody negative patients despite similar exposure of a similar number of patients; in contrast, the attack rate among our HIV antibody positive inpatients was $19 \%$. Secondly, our analysis of risk factors showed consistent trends, though individually not significant, towards more advanced HIV disease among patients developing symptomatic cryptosporidiosis, indicating a relation between immunity and infectious dose. Thirdly, the analysis strongly points to treatment with oral sulphonamides as an important risk factor. In experimental studies the inoculum required for establishing clinical infection with enteric organisms may be reduced dramatically when the host is pretreated with oral antibiotics. ${ }^{14}$ Whether oral sulphonamides independently increase the risk of acquiring cryptosporidiosis will require further studies.

Recovery from diarrhoea was seen in $31 \%$ of the patients, which corresponds to reported figures. ${ }^{312} \mathrm{We}$ did not see an unequivocal positive effect of any of the treatments tried. The recovery rates in uncontrolled treatment $\operatorname{trials}^{101516}$ are of the same magnitude as the rate of spontaneous recovery, underscoring the unreliability of such studies.

Only a few reports of nosocomial spread of cryptosporidiosis exist. In one case five of six patients in a bone marrow transplant unit contracted cryptosporidiosis; all ultimately recovered,${ }^{8}$ but the mode of spread was not discovered. In another report spread of cryptosporidiosis from an AIDS patient to staff members was described. ${ }^{17}$

The present outbreak of hospital acquired cryptosporidiosis is thus the most serious to date, both as regards number of cases and number of deaths attributable to diarrhoea. Routine precautions against transmission of enteric organisms were in use throughout the outbreak, and we found no case for using more restrictive guidelines. Continent, cooperative patients need not be isolated in their rooms. The painful lesson from this outbreak is not that the guidelines were insufficient, but that their non-observance may have serious consequences.

1 Nime FA, Burek JD, Page DL, Holscher MA, Yardley JH. Acute enterocolitis in a human being infected with the protozoan cryptosporidium. Gastroenterology 1976;70:592-8.

2 Holten-Andersen W, Gerstoft J, Henriksen SV A, Pedersen NS. Prevalence of cryptosporidium among patients with acute enteric infection. $\mathcal{I}$ Infect 1984;9:277-88.

3 Casemore DP. Epidemiological aspects of human cryptosporidiosis. Epidemiol Infect 1990;104:1-28.

4 Navin TR, Hardy AM. Cryptosporidiosis in patients with AIDS. I Infect Dis 1987:155:150.

5 Petersen C, Gerstoft J, Tauris P, et al Opportunistic infections and malignancies in 231 Danish AIDS patients. AIDS 1990;4:233-8.

6 Henriksen SA, Pohlenz JFL. Staining of cryptosporidia by a modified ZiehlNenriksen SA, Pohlenz JFL. Staining of cryptosporidia

7 Current WL. The biology of cryptosporidium. American Society for Microbiology News 1988;54:604-11.

8 Martino P, Gentile G, Caprioli A, et al. Hospital acquired cryptosporidiosis in a bone marrow transplant unit. F Infect Dis 1988;158:647-8.

9 Jokipii AMM, Hemla M, Jokipii L. Prospective study of acquisition of 
cryptosporidium, Giardia lamblia and gastrointestinal illness. Lancet 1985; ii; $487-9$.

10 Rolston KVI, Fainstein V, Bodey GP. Intestinal cryptosporidiosis treated with eflornithine: a prospective study among patients with AIDS. Fournal of Acquired Immunodeficiency Syndromes 1989;2:426-30.

11 Zar F, Geisler PJ, Brown VA. Asymptomatic carriage of cryptosporidium in the stool of a patient with acquired immunodeficiency syndrome. $\mathcal{F}$ Infect $D i$ is 1985; 151:195

12 Janoff EN, Limas C, Penley KA. Cryptosporidial carriage without symptoms in the acquired immunodeficiency syndrome (AIDS). Ann Intern Med 1990;112:75.

13 Høilyng N, Mølbak K, Jepsen S. Cryptosporidium spp. a frequent cause of diarrhoea in Liberian children. $\mathcal{F}$ Clin Microbiol 1986;23:1109-13.
14 Hornick RB, Greisman SE, Woodward TE, DuPont HL, Dawkins AT, Snyder MJ. Typhoid fever: pathogenesis and immunologic control. New Engl f Med 1970;13:686-746.

15 Connolly GM, Dryden MS, Shanon DC, Gazzard BG. Cryptosporidial diarrhoea in AIDS and its treatment. Gut 1988;29:593-7.

16 Ungar BLP, Ward DJ, Fayer R, Quinn CA. Cessation of cryptosporidiumassociated diarrhoea in an acquired immunodeficiency syndrome patient after treatment with hyperimmune bovine colostrum. Gastroenterology 1990;98:486-9.

17 Koch KL, Phillips DJ, Aber RC, Current WL. Cryptosporidiosis in hospital personnel. Ann Intern Med 1985;102:593-6.

(Accepted 21 November 1990)

\section{For Debate}

\section{What will the medical director do?}

\section{Ian H Johnston}

Among the wide range of new arrangements and roles either implied or introduced by the new organisation of the NHS there is one which has received little attention, yet is potentially very significant - that is, the role of the medical director, one of the required (in most cases) executive directors of boards of NHS trusts.' It is curious that this development should have received such little attention. Most potential trusts are hospitals whose aim will be to deliver and develop good quality medical services, and ensuring this must be the prime focus of the boards of directors. Without such a focus a board would be equivalent to a manufacturer not being concerned with the quality of a product. The medical director will have the key responsibility both for ensuring that the focus is maintained and for informing the board of what is requisite. However, before attempting to clarify further the role of a medical director we should be reminded of some features of the post that may be deduced from the NHS and Community Care Act and the working papers which supplemented the white paper Working for Patients.

Firstly, the medical director is appointed by the chairman, the non-executive directors, and the general manager. ${ }^{2}$ Though it would be preferable that the person appointed had the confidence of the medical staff, the post of medical director is not a representative appointment but an executive one, in which corporate responsibility is shared as a member of the board and responsibility is to the general manager. Indeed, no member of a trust board is a representative member, which is one reason why chairmen of medical advisory committees should not become medical directors. Doctors will continue to require independent representative machinery but it would be a confusion of role and interests if one doctor were to attempt to have both an executive and a representative role. (This is, of course, one of the problems that has had to be faced repeatedly by unit medical representatives over the years.)

Secondly, the original working paper says that it might be possible to combine the medical directorship with some clinical work. ${ }^{2}$ There clearly exists an expectation that the position requires more than regular attendance at board meetings to represent the views of doctors. In fact, the most powerful reason why this position cannot be combined with a representativethat is, elected-position is that it actually requires a full time executive contribution to developing a trust's services. This assertion is based on an analysis of the work that will be required within the new arrangements for the NHS - in particular, on that required in a large teaching hospital with a wider range of specialties than most hospitals in the United Kingdom. The following is based on the needs of the General Infirmary at Leeds, but is applicable to any large hospital considering NHS trust status.

The major general areas for which a hospital of this size requires appointment of a senior doctor with responsibility for development are as follows.

\section{- Medical services}

- Clinical research

- Medical education

- Medical input into contracts for services.

In these areas development can be led only by a doctor, and the position is referred to in the white paper as medical director. This does not imply any line management authority over consultant medical staff, nor does what follows here. What, then, will the medical director do?

\section{Medical services}

The medical director's responsibility is to develop the comprehensive provision of medical services and to advise how they contribute to the aims and priorities of the trust. Currently, unless the director of public health attempts this, no individual has this responsibility. The specific responsibilities that would flow from this include the following:

- To overview and advise on arrangements for ensuring that the general performance of medical services in all specialties is efficient and in line with current medical practice and to satisfy the general manager and the board that the arrangements are adequate. An important way of achieving this is through facilitating and supporting the implementation and development of medical audit

- To review existing medical services, identifying any shortfalls in the range of services provided and to proposing means for dealing with them

- To enhance the relation of medical specialties with one another, ensuring that they dovetail as appropriate, including undertaking any arbitration between specialties, as necessary

- To help the general manager in handling consultant contracts

- To develop and facilitate the participation of consultants in management, in particular, in giving direction to the trust

- To establish arrangements for obtaining medical opinions on priorities for development (or retrenchment) and ensure that these priorities are consistent with financial and other considerations

- The role of the board of directors should not be confused here with that of management boards, whose 